\title{
Robotics as an Educational Tool: Impact of Lego Mindstorms
}

\author{
E. Afari and M. S. Khine
}

\begin{abstract}
It is increasingly important that next generation of students must acquire problem solving, critical thinking and collaborative skills to succeed in their career aspirations in the 21st century. Technology plays a crucial role in assimilation of these skills. Among flourishing arrays of technologies, robotics provides challenges and opportunities to the learners in developing innovative ideas, disruptive thinking and higher order learning skills. In recognizing these potentials, educational authorities in the United Arab Emirates (UAE) undertook an important step in distributing Lego Mindstorms kits to schools to encourage teachers to use in their teaching. This paper explores the educational use of robotics in schools and how teachers can integrate this new technology into the curriculum. The paper also suggests the effective strategies in using robotics as an educational tool and how it will impact students' interests in STEM related subjects. Some recommendations to enhance learning activities in the classrooms are provided.
\end{abstract}

Index Terms-Educational robotics, Lego Mindstorms, STEM education.

\section{INTRODUCTION}

Robotics has attracted high interest of teachers and researchers as a valuable tool to develop cognitive and social skills for students from pre-school to high school and to support learning in science, mathematics, technology, informatics and other school subjects or interdisciplinary learning activities during the last decade [1]. According to [2] educational robotics has emerged as a unique learning tool that can offer hands-on, fun activities in an attractive learning environment, feeding students interest and curiosity.

Review of literature has revealed that Educational Robotics is a growing field with the potential to significantly impact the nature of science and technology education at all levels, from kindergarten to university [1]. Over the years, a number of robot construction kits for edutainment applications have been designed to improve and increase interaction between users and robotics artifacts [3]- [6].

According to [7], some robots have a static morphology (e.g. Furby), while others have one which is variable (e.g. Lego® Mind-Storms ${ }^{\mathrm{TM}}$, Fischer Technic robot). Robots with variable morphology give the user the opportunity to build, plan and program different kinds of robotics artifacts and has been built in accordance with learning principles derived from Piaget and Vygotskij's theories [8]-[10] of cognitive development, as revised by [11], which portray learning as the

Manuscript received February 25, 2016: revised March 12, 2016.

E. Afari is with the Petroleum Institute, Abu Dhabi, UAE (e-mail: ernest.afari@gmail.com).

M. S. Khine is with Emirates College for Advanced Education, Abu Dhabi, UAE (e-mail: dr.mkhine@gmail.com). acquisition or 'construction' of knowledge through observation of the effects of one's actions on the world [12]. The constructivist approach promotes a kind of learning in which the educator does not transfer information, but is rather a facilitator of learning, leading the working group, and so the learner enhances his/her knowledge through the manipulation and construction of physical objects [13].

Numerous researchers have endorsed Robotics as an educational tool [14]-[17], with a number of literature devoted solely to using the Lego MindStorms kit [18], [19], at levels ranging from primary school to University [20]-[22]. According to [23], there are reports of improved performance in Mathematics, Physics, and Engineering courses resulting from educational Robotics projects, although most of the evidence is based on the reports of teachers achieving positive outcomes through individual initiatives [24].

According to [25], Robotics offers special educational leverage, because it is multi-disciplinary field involving a synthesis of many technical topics, including Mathematics and Physics, Design and Innovation, Electronics, Computer Science and Programming, and Psychology. Results of past research have suggested that the pedagogical value of robots lies in making them work, through using or extending knowledge to identify problems, and argues that robots are a particularly motivating technology because they are concrete, complex, and relate to deep human needs [13].

\section{ROBOTICS IN EDUCATION}

Studies in the field of robotics have reported that robotics have a potential impact on students' learning in different subject areas (Physics, Mathematics, Engineering, Informatics and more) and on personal development including cognitive, meta-cognitive and social skills, such as: research skills, creative thinking, decision making, problem solving, communication and team working skills, all of them being essential skills necessary in the workplace of the $21 \mathrm{st}$ century [2], [26].

STEM education is an educational approach that integrates Science, Technology, Engineering and Mathematics into a cohesive learning paradigm based on real-world application. Given the current shortage of student interest in STEM education, increased attention has been given to the appeal and attraction of Robotics [27]. As stated by [28], educational robotics is an effective tool for project-based learning where STEM, coding, computer thinking and engineering skills are all integrated in one project. Educational robotics is rich with opportunities to integrate not only STEM but also many other disciplines. It gives students the opportunity to find new ways to work together to encourage collaboration skills, express 
themselves using the technological tool, problem-solving, and think critically and innovatively.

Educational robotics is a learning tool that enhances student experiences through hands-on mind-on learning. It also provides a fun and exciting learning environment because of its hands-on nature and the integration of technology [28]. The engaging learning environment motivates students to learn whatever skills and knowledge needed for them to accomplish their goals in order to complete the projects of their interest [28]. Pioneering efforts in school classes during last decade have shown that children are enthusiastically involved in robotics projects achieving learning goals and/or developing new skills (e.g. [29], [30].

In the last decades, in several places in the world, a number of experiments with the use of Robotics in educational activities have been conducted. These have focused mainly on university education, although a number of these experiments have also been conducted in secondary and elementary levels. Robots can be an entertaining platform to learn about computers, electronics, mechanical engineering and languages. It has been shown that young children performed better on post-learning examinations and generated more interest when language learning took place with the help of a robot as compared to audiotapes and books [31].

Educational theorists such as [32] believe that robotics activities have tremendous potential to improve classroom teaching. However, [33] affirmed that there is limited empirical evidence to prove the impact of robotics on the k-12 curriculum [26].

Educators have started to generate ideas and develop activities to incorporate robotics into the teaching of various subjects, including math, science, and engineering. However, [34] argued that without research evidence to support their direct impact on students' academic performance, robotics activities may be just a "fashion". Researchers have highlighted that most of the literature on the use of robotics in education is descriptive in nature, based on reports of teachers achieving positive outcomes with individual initiatives [33], [35], [36].

Many researchers believe that robotics provides a tremendous source of energy that can be used to motivate children's learning. However, [34] cautioned that we need to understand what exactly robotics has to offer to the educator before jumping into conclusions.

Ref. [26] identified the potential contribution of the incorporation of robotics as educational tool in schools, and presented a synthesis of the available empirical evidence on the educational effectiveness of robotics as an educational tool in schools. Ref. [26] reviewed recently published scientific literature on the use of robotics in schools. In general, the results of the articles showed a learning gain with the use of robotics [33]. However, other articles reported situations in which there was no improvement in learning [37]-[39].

According to [40], robotics can be used for discovery learning, collaborative learning, problem solving, and project-based learning in education. However, they believe that these approaches have to be reshaped towards the context of modern society. They proposed some ways to use robotics as a tool for learning physics through experiments that are set up according to inquiry learning stages (setting research questions, hypothesizing, planning experiments, collecting data, analyzing, making conclusions). Ref. [40] recommended that robotics and inquiry learning could also be used in other STEM subjects as well.

Ref. [41] noted that robotics can be used as MindTools in education. The positive learning results from two case studies on physics and programming teaching indicated that educational robotics can be used as MindTools supporting knowledge construction through the design of meaningful authentic projects, learning by doing in both the virtual and real world, facing cognitive conflicts and learning by reflection and collaboration.

The review of [42] showed that robots are primarily used to provide language, science or technology education and that a robot can take on the role of a tutor, tool or peer in the learning activity.

\section{LEARNING APPROACHES APPLIED IN ROBOTICS EDUCATION}

The main theories behind educational robotics are constructivism and constructionism [1]. As agued by Piaget, manipulating artefacts is a key for children to construct their knowledge [32]. Educators" role is to offer opportunities for children to engage in hands-on explorations and to provide tools for children to construct knowledge in the classroom environment [1]. Educational Robotics creates a learning environment in which children can interact with their environment and work with real-world problems.

Robotics education can be traced to constructivism [43]-[45]. The constructionism is based on the idea that human beings learn better when they are involved in planning and building artefacts that are significant to them and they share this with the community. The integration of robotics in education can provide students the opportunity to develop interactive thinking [11], [32], [46], [47]. Within a constructivist learning environment, students have the opportunity to manage their learning. Also, students are able to cultivate mathematical and scientific skills. Students are able to understand the connection between theory and practice, as well link what they learn within the classroom to reality and nature [5], [48].

Ref. [49] suggested that teachers can design activities through the use of robotics that help students to explore new concepts and new ways of thinking. According to [50], students can develop their technological literacy and engineering skills through these activities. Studies conducted by [51] and [45] revealed that robotics used as educational tool might help students to develop the knowledge and skills required in order to survive in the ever-changing, interconnected information society era of the 21 st century.

\section{LEGO MINDSTORMS}

Lego Mindstorms is an assembly kit that contains building block pieces and a programmable control unit that can enable one to build a number of robots. Among different models available, Ev3 is particularly designed for educational use. A 
typical kit includes all the necessary components for developing simple haptic interfaces including sensors, motors, a programmable controller and an assortment of mechanical components. The components are in the form of gears, belts, shafts, wheels and connectors. The standard Mindstorms set also includes four sensors that are useful in robotic devices. These are touch, sound, light and infrared sensors. The touch sensor is a switch for detecting contact or controlling program execution. The sound sensor which is a microphone that can be used to detect or record sounds. The light sensor is used to differentiate between light and dark and infrared sensor which measures the distance to an object and can be used to avoid obstacles, follow target and detect motion [52]. The main component in Lego system is the Ev3 brick and it is a small computer that controls a robot's motors and sensors, enabling the robot to move around by itself. The Lego Mindstorms allows users to assemble robots, program the movement, interface sensors and motors without focusing on technical details. The process of assembling and making the robot work involve basic understanding of physical and design principles and elementary programming skills [53].

Ref. [54] noted that Lego Mindstorms is suitable to use in educational settings due to the following reasons.

Versatility: The system allows students to design, built and program a variety of devices by using ready made plans or the plans that are shared by other users. The reusable nature of Lego bricks allows students to design, built and test easily without requiring special assembly skills.

Student appeal: Lego Mindstorms are popular among children who are used to play with other mechanical devices. Students are keen to get hand-on experience in assembling different parts and create a moving device. Students gain immediate satisfaction once they can successfully build a robot.

Features: The Lego Mindstorms kit includes all necessary components to build variety of robots with the use of sensors, motors and programmable device that control the movement and reaction of the robot.

\section{RoBOtICS INITIATIVES IN THE UAE}

The United Arab Emirates Government has recently launched UAE AI and Robotics Award for Good, with the intention to support innovation in the key area of artificial intelligence and robotics as part of the UAE's commitment towards the National Innovation Strategy. This initiative offers a first of its kind global platform for innovation, focusing on the practical side of this technology in areas of much relevance to the society such as health, education and social services. The prize awards includes USD 1 million for international competition and AED 1 million for national competition for the best use of robotics and $\mathrm{AI}$ in improving people's lives [55].

In line with its vision to adopt sustainable education based on technology, the Ministry of Education has implemented two major projects in public schools to equip students with scientific skills, and enhance their innovative thinking and creativity. In the first project, 'Robot Bag', the ministry provided 250 public schools with 'Robot Bags' during the past four years as part of its efforts to enable the students to participate in the 'Robot Olympics' which will be launched by the ministry. The ministry also provided 54 schools with high quality 'technology bags' as part of its project 'Globe'. These bags contain tools that can assist students in environmental research, and enhance their capabilities to conduct scientific research and develop real solutions for key environmental issues [56].

The educational authority in Abu Dhabi, Abu Dhabi Education Council (ADEC) has been actively involved in promoting the use of robotics in schools as educational tool. The aim of ADEC is to encourage students to engage in innovative and creative activities that require STEM related knowledge.

The educational planners are aware that robotics is a wonderful platform for learning 21 st century skills. Solving robotic challenges builds innovation, creativity and problem solving skills in students, and because robotics crosses multiple curriculum subjects, students must learn and apply their knowledge in science, engineering, math, and computer programming. The most rewarding part of designing robots is that students have fun, work together as a team, and learning occurs naturally. Throughout the world, robotics is recognized as a popular way to get young children interested in science, math, engineering and technology. Many students are very excited at the thought of building and programming robots.

In 2008, ADEC was appointed National Organizer of the World Robot Olympiad (WRO) in the United Arab Emirates. The World Robot Olympiad is an event that brings young people together from all over the world. It is a combination of science, technology and education. This event will allow these young people the opportunity to develop through various robotic challenges and competitions. During 2009, the program to equip schools with Lego robotics kits was expanded to include all Abu Dhabi public schools catering for Grade 3 upwards. By the end of 2010, junior robotics kits were supplied to public schools catering for Grades $1-3$. The Emirate's Private Schools and other significant educational institutions were invited to participate in the program during 2011. The robotics program targeted improving science, technology, engineering and mathematics skills and knowledge of students, while focusing on the development of their problem solving, creativity, innovation and collaboration skills and aptitudes. ADEC believes that robotics offers students a real challenge. It can be used to aid in preparing students for the future requiring them to be active in their learning.

The ADEC Robotics in Education Program had its beginning in 2007, when the concept of participating in robotics competitions was bought to the Council's attention. The objectives and outcomes of these competitions complemented those of ADEC. According to ADEC, WRO in the UAE has been growing rapidly. In 2008, 29 teams participated in the Challenge. In 2011, 602 teams participated across the UAE. Over 300 teams competed during 2012 in a competition with a reduced number of categories, while in 2014 more than 420 teams competed [57].

ADEC organized WRO UAE National Robotic challenge which took place on September 27th - 28th 2015 in Abu 
Dhabi (See fig 1). 300 teams including students from different age groups across public and private schools in the UAE took part in the competition. The teams competed in three different categories, namely: (open category, regular category and Football WRO GEN II category). 18 out of 300 teams were selected to participate in WRO International finals held in Doha, Qatar which was held on November 6 - 8th 2015 under the theme "ROBOT EXPLORERS." The World Robot Olympiad (WRO) is a LEGO Mindstorms based robotics competition with categories and age groups catering for students from Grades 3 to University Level. The competition is hosted in a different country each November, with over 50 member countries and more than 20,000 teams competing in the challenge annually. The competition is designed to develop skills and inspire enthusiasm in science, technology, engineering and mathematics (STEM) by bringing together teams of young people from all over the world and challenging them to use their creativity and problem-solving skills to build robots capable of completing a range of challenges.

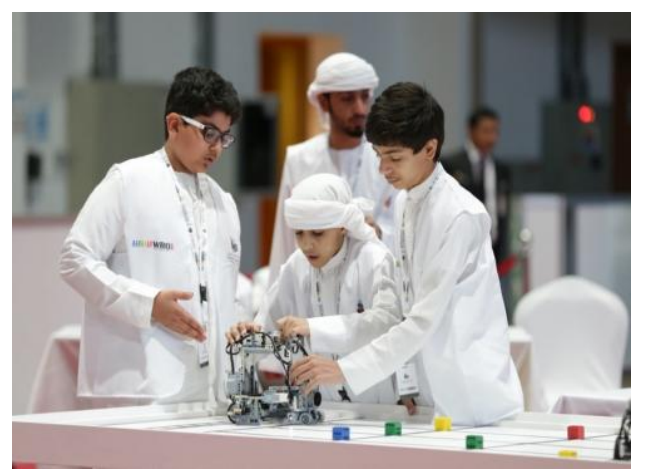

Fig. 1. Students competing in a WRO National competition in Abu Dhabi [58].

The WRO initiative is part of ADEC's 10-year strategy plan to provide students with world class technology education through innovative and challenging Science, Technology Engineering, Mathematics (STEM) related activities. According to Dr. Najla Al Naqbi (ADEC's e-Learning Program Manager) the aim of ADEC is to encourage students to think critically, apply knowledge, reach solutions, work as a team under pressure, and experiment in a very short time span. Dr. Al Naqbi has also mentioned that ADEC will continue to encourage students to take part in WRO and similar innovative activities that require them to think critically, teamwork and challenge [58].

The 2016 WRO and First Lego League (FLL) will be held in India under the theme "Rap the Scrap" - which includes designing robots to help reduce, manage and recycle waste. The Regular Category for the competition includes three different challenges for elementary, junior high and senior high students. The challenge for elementary students comprised of designing a robot to help a child clean during his or her journey to school, starting with making the bed, all the way to cleaning the school's playground. The junior high challenge includes designing a robot to collect certain kinds of recyclable waste from home into recycling waste bins to be picked up by the Municipal Service. The senior high challenge includes making a robot that brings sorted waste stored in recycling containers to the corresponding recycling tank at a waste recycling plant.

ADEC is organizing the 2016 UAE National Robot Challenge to help qualify winning students to take part in the 2016 WRO and FLL in India. ADEC has therefore invited over 400 coaches, teachers and mentors of robotic teams and clubs, to learn more about the UAE National Robot Challenge to be held on June 2016. ADEC has implemented robotic clubs and innovation initiatives and are confident that they are more than capable in winning some of the educational robot competitions. With ADEC's robotic initiatives, students in the UAE are now intrigued to learn more about STEM education, since it encourages them to challenge their problem solving skills and become innovative, creative, think critically and search for solutions

\section{CONCLUSION}

In this paper the concept of using robotics as an educational tool and the features of Lego Mindstorms have been described. In the 21st century learning context, engaging students with technology is an important pedagogy to gain attention and increase motivation among students. It is evident that the use of robotics will improve the students' problem solving and algorithmic skills. The students will also have an opportunity to engage with authentic activities. Such experience is essential in transfer of learning to the real life scenarios. Additionally, the process of planning, assembling and operating robots can stimulate creative thought and encourage critical thinking. Robotic learning usually take place in groups and collaboration among peers and social interaction process can further enhance the complex learning process.

By recognizing the potential of robotics learning, educational planners around the world are implementing various initiatives in schools to provide opportunity for students of all ages to learning with robots. It is expected that these initiatives will grow further in the years to come and teachers and students can fully exploit the efficacies of robotics. It has been well recognized that the world is changing rapidly and innovative ways of teaching are necessary to scaffold the learners and challenge them with novel problems. Robotics will play a crucial role in achieving this.

\section{REFERENCES}

[1] D. Alimisis, "Educational robotics: New challenges and trends," Themes in Science and Technology Education, vol. 6, pp. 63-71, 2013.

[2] A. Eguchi, "What is educational robotics? Theories behind it and practical implementation," in Proc. Society for Information Technology \& Teacher Education International Conference.

[3] R. Balogh, "Basic activities with the Boe-Bot mobile robot," in Proc. Conference DidInfo, FPV UMB, Banská Bystrica, Slovakia, 2008.

[4] A. Eguchi and J. Reyes, "Engage and motivate non-computer science major undergraduates using educational robotics," in Proc. Society for Information Technology and Teacher Education International Conference, pp. 2572-2576, 2008.

[5] O. Miglino, H. H. Lund, and M. Cardaci, "Robotics as an educational tool," Journal of Interactive Learning Research, vol. 10, no. 1, pp. 25-47, 1999.

[6] E. Sklar, S. Parsons, M. Q. Azhar, and V. Andrewlevich, "Educational robotics in Brooklyn (short version)," in Proc. the AAAI Mobile Robo Workshop, 2006.

[7] H. H. Lund and L. Pagliarini, "Edutainment robotics: Applying modern AI techniques," in Proc. International Conference on 
Autonomous Minirobots for Research and Edutainment, AMIRE, 2001.

[8] J. Piaget and B. Inhelder, The Psychology of the Child, New York, NY: Basic Books, P.U.F., 2000

[9] J. Piaget, Genetic Epistemology, New York: W.W. Norton, 1971.

[10] L. S. Vygotskij, Mind in Society: The Development of Higher Psychology Processes, Cambridge, MA: Havard University Press, 1974.

[11] S. Papert, Constructionism: A New Opportunity for Elementary Science Education, MIT: Media Laboratory-Epistemology and learning group, Cambridge, 1986

[12] S. Papert and I. Harel, Constructionism, Ablex Publishing, Norwood, 1991.

[13] E. Bilotta, L. Gabriele, R. Servidio, and A. Tavernise, "Edutainment robotics as learning tool," Transactions on Edutainment III, vol. 2, no. 2, Springer Berlin: Hei-delberg, pp. 25-35, 2009.

[14] B. Denis and S. Hubert, "Collaborative learning in an educational robotics environment," Computers in Human Behavior, vol. 17, 465-480, 2001.

[15] D. Kumar and L. Meedan, "A robot laboratory for teaching artificial intelligence," in Proc. the ACM SIGCSE symposium, pp. 341-344, ACM Press, New York, 1988.

[16] B. Nostrand, "Autonomous robotics projects for learning software engineering," in Proc. IEEE, 2000.

[17] J. B. Weinberg, G. L. Engel, K. Gu, C. S. Karacal, S. R. Smith, W. W. White, and X. W. Yu, "A multidisciplinary model for using robotics in engineering education," in Proc. the 2001 ASEE Annual Conference and Exposition, 2001.

[18] F. Klassner and S. Anderson, "Lego mindstorms: Not just for K-12 anymore," IEEE Robotics and Automation Magazine, 2003.

[19] M. Marcinkiewicz, M. Kunin, S. Parsons, E. Sklar, and T. Raphan, "Towards a methodology for stabilizing the gaze of a quadrupedal robot," Robot Soccer World Cup X. LNCS (LNAI), vol. 4434, pp. 540-547, Springer, Heidelberg, 2007.

[20] M. Moundridou and A. Kalinoglou, "Using LEGO mindstorms as an instructional aid in technical and vocational secondary education: Experiences from an empirical case study," LNCS, vol. 5192, pp. 312-321, Springer, Heidelberg, 2008.

[21] P. Petrovic and R. Balogh, "Educational robotics initiatives in Slovakia," Teaching with Robotics, 2008.

[22] M. Petre and B. A. Price, "Using robotics to motivate back door learning," Education and Information Technologies, vol. 9, no. 2, pp. $147-158,2004$

[23] M. U. Bers and M. Portmore, "Teaching partnerships: Early childhood and engineering students teaching math and science through Robotics," J of S. Edu, and Tech., vol. 14, pp. 59-73, 2005.

[24] S. Yoon, E. Pedretti, L. Pedretti, J. Hewitt, K. Perris, and R. Oostveen, $\mathrm{R}$, "Exploring the use of cases and case methods," J. of S. Tea Educ. vol. 17 , no. 1 , pp. $15-35,2006$.

[25] J. Johnson, "Children, robotics, and education," in Proc. 7th International Symposium on Artificial Life and Robotics (AROB-7), pp. 491-496, 2002.

[26] F. B. V. Benitti, "Exploring the educational potential of robotics in schools: A systematic review," Computers \& Education, vol. 58, no. 3, pp. 978-988, 2012

[27] A. Sergeyev, N. Alaraje, S. Kuhl, M. Meyer, M. Kinney, and M. Highum, "Innovative curriculum model development in robotics education to meet $21^{\text {st }}$ century workforce needs," in Proc. the 2015 ASEE Zone III Conference, Springfield, Missouri, US, 2015.

[28] A. Eguchi, "Educational robotics for promoting $21^{\text {st }}$ century skills," Journal of Automation, Mobile Robotics \& Intelligent Systems, vol. 8, no. 1, 5-11, 2014.

[29] N. Detsikas and D. Alimisis, "Status and trends in educational robotics worldwide with special consideration of educational experiences from Greek schools," in Proc. the International Conference on Informatics in Schools: Situation, Evolution and Perspectives, pp. 1-12, Bratislava: Comenius University, 2011.

[30] A. Litinas and D. Alimisis, "Planning, implementation and evaluation of lab activities using robotic technology for teaching the phenomenon of motion," in Proc. the 3rd Pan-Hellenic Conference Integration and Use of ICT in Educational Process, Piraeus: HAICTE \& University of Piraeus (in Greek), 2013.

[31] J. Han, V. Jones, and J. H. Jo, "Comparative study on the educational use of home robots for children," Journal of Information Processing Systems, vol. 4, no. 4, pp. 159-168, 2008.

[32] S. Papert, Mindstorms: Children, Computers, and Powerful Ideas, NY, New York: Basic Books, 1993.
[33] D. Williams, Y. Ma, L. Prejean, G. Lai, and M. Ford, "Acquisition of physics content knowledge and scientific inquiry skills in a robotics summer camp," Journal of Research on Technology in Education, vol. 40, no. 2, pp. 201-216, 2007.

[34] J. Johnson, "Children, robotics and education," in Proc. 7th international symposium on artificial life and robotics, vol. 7, pp. 16-21, Oita, Japan, 2003.

[35] B. Caci, M. Cardaci, and H. H. Lund, "Assessing educational robotics by the "Robot edutainment questionnaire," Technical Report, The Maersk Mc-Kinney Moller Institute for Production Technology, University of Southern Denmark, 2003.

[36] M. Petre and B. A. Price, "Using robotics to motivate back door learning," Education and Information Technologies, 2004, vol. 9, no. 2, pp. 147-158.

[37] S. Hussain, J. Lindh, and G. Shukur, "The effect of LEGO training on pupils' school performance in mathematics, problem solving ability and attitude: Swedish data," Journal of Educational Technology and Society, vol. 9, no. 3, pp. 182-194, 2006.

[38] J. Lindh and T. Holgersson, "Does lego training stimulate pupils" ability to solve logical problems?" Computers \& Education, vol. 49, no. 4, pp. 1097-1111, 2007.

[39] B. S. Barker and J. Ansorge, "Robotics as means to increase achievement scores in an informal learning environment," Journal of Research on Technology in Education, vol. 39, no. 3, pp. 229-243, 2007.

[40] H. Altin and M. Pedaste, "Learning approaches to applying robotics in science education," Journal of Baltic Science Education, vol. 12, no. 3, pp. 365-377, 2013

[41] T. A. Mikropoulos and I. Bellou, "Educational robotics as mindtools," Themesin Science \& Technology Education, 2013, vol. 6, no. 1, pp. $5-14$.

[42] O. Mubin, C. J. Stevens, S. Shahid, A. Al Mahmud, and J-J. Dong, “A review of the applicability of robots in education," Technology for Education and Learning, 2013, pp. 1-7.

[43] A. Bauerle and M. Gallagher, "Toying with technology: Bridging the gap between education and engineering," in Proc. Society for Information Technology \& Teacher Education International Conference 2003, pp. 3538-3541, Chesapeake, VA: AACE, 2003.

[44] S. Papert, Mindstorms: Children, Computers, and Powerful Ideas, NY, New York: Basic Books, 1980

[45] D. Williams, Y. Ma, and L. Prejean, "A preliminary study exploring the use of fictional narrative in robotics activities," Journal of Computers in Mathematics and Science Teaching, vol. 29, no. 1, pp. 51-71, Chesapeake, VA: AACE, 2010.

[46] Y. Kafai and M. Resnick, Constructionism in Practice: Designing, Thinking and Learning in a Digital World, Mahwah, NJ: Lawrence Erlbaum, 1996.

[47] I. Harel and S. Papert, Constructionism, NJ: Ablex, 1991.

[48] F. R. Sullivan and M. A. Moriarty, "Robotics and discovery learning: Pedagogical beliefs, teacher practice and technology integration," Journal of Technology and Teacher Education, vol. 17, no. 1, pp. 109-142, Chesapeake, VA: AACE, 2009.

[49] J. M. Chambers and M. Carbonaro, "Designing, developing, and implementing a course on LEGO Robotics for technology teacher education," Journal of Technology and Teacher Education, vol. 11, no. 2, pp. 209-241, 2003.

[50] M. U. Bers, I. Ponte, C. Juelich, A. Viera, and J. Schenker, "Teachers as designers: Integrating robotics in early childhood education," Information Technology in Childhood Education Annual, vol. 2002, no. 1, 123-145, 2002.

[51] M. Talaiver and R. Bowen, "Developing $21^{\text {st }}$-century skills: Game design and robotics exploration," I in Proc. Society for Information Technology Education International Conference 2010, pp. 2089-2090, Chesapeake, VA: AACE

[52] L. Valk, Lego Mindstorms Ev3 Discovery Book: A Beginner's Guide to Building and Programming Robots, San Francisco: No Starch Press, 2014.

[53] J. Chetty, "Lego $\odot$ mindstorms: Merely a toy or a powerful pedagogical tool for learning computer programming?" in Proc. the 38th Australasian Computer Science Conference (ACSC 2015), vol. 27, pp. 30, 2015, January.

[54] A. M. Brandt and M. B. Colton, "Toys in the classroom: LEGO mindstorms as an educational haptics platform," in Proc. Haptic Interfaces for Virtual Environment and Tele Operator Systems Conference, 2008, pp. 389-395, IEEE.

[55] UAE AI and robotics award for good. [Online]. Available www.roboticsforgood.ae 
[56] UAE Ministry of Education and 'Robot Bags'. [Online]. Available: http://uaecabinet.ae/en/details/news/ministry-of-education-provides-2 50-schools-with-robot-bags

[57] ADEC Robotics in Education Program. [Online]. Available: https://www.adec.ac.ae/en/students/athleticeducation/pages/world-rob ot-olympiad.asp

[58] The 2015 WRO-UAE national robotics challenge. [Online]. Available: https://www.adec.ac.ae/en/MediaCenter/News/Pages/The-2015-WRO -UAE-National-Robotics-Challenge.aspx

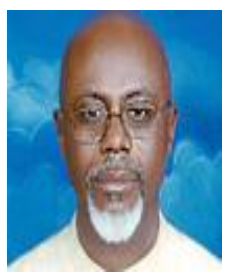

Ernest Afari is a mathematics lecturer at the Petroleum Institute in Abu Dhabi, United Arab Emirates (UAE). He received the $\mathrm{PhD}$ from Curtin University, Perth, Western Australia and the MSc (mathematics) from the University of British Columbia, Vancouver, British Columbia, Canada. His research focuses on factor analysis, structural equation modeling, psychometrics and application of statistical procedures to education.

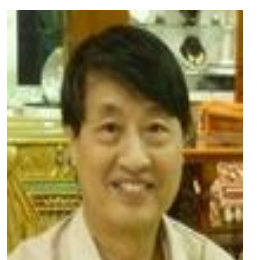

Myint Swe Khine is a professor and program chair of Assessment and Evaluation Centre at the Emirates College for Advanced Education in Abu Dhabi, United Arab Emirates. He earned the master degrees from the University of Southern California, USA and University of Surrey, UK, and the doctor of education from Curtin University, Perth, Australia. He publishes widely in international referred journals and edited several books. 